\title{
"Clinical Profile of Children with Birth Asphyxia: A Retrospective Study in Khulna Medical College, Hospital"
}

Dr. Nityananda Baruri ${ }^{1}$, Dr. Shams Ibne Maksud ${ }^{2}$, Md. Muhammad Syeeful Ameen ${ }^{3}$

${ }^{1}$ Assistant Professor (MBBS, DCH), Department of Pediatric, Khulna Medical College Hospital, Khulna, Bangladesh
${ }^{2,3}$ Assistant professor, Department of Paediatrics, Shaheed Monsur Ali Medical College and Hospital, Dhaka, Bangladesh

DOI: $10.36347 /$ sjams.2020.v08i10.041

| Received: 03.10.2020 | Accepted: 19.10.2020 | Published: 30.10.2020

*Corresponding author: Dr. Nityananda Baruri

Abstract

Original Research Article

Introduction: Birth asphyxia is defined by the World Health Organization "the failure to initiate and sustain breathing at birth." The WHO has estimated that 4 million babies die during the neonatal period every year and $99 \%$ of these deaths occur in low-income and middle income countries. Three major causes account for over three quarters of these deaths, serious infection (28\%) complication of preterm birth (26\%) and birth asphyxia (23\%). This estimation implies that birth asphyxia is the cause of around one million neonatal deaths each year. One of the present challenges is the lack of a gold standard for accurately defining birth asphyxia. Because of same reason the incidence of birth asphyxia is difficult to quantify in Khulna Medical College, Khulna, Bangladesh. Aim of the Study: The aim of this study was to find out the clinical outcome of birth asphyxia, identify the common obstetric and neonatal risk factors, and study the cause of death. Material \& Methods: Between Jan 2019 and Dec 2019, there were 114 live births asphyxiated neonates whose were clinically diagnosed and admitted in the department of pediatrics at Khulna Medical College Hospital, Khulna, Bangladesh in the mentioned hospital were finalized as the study population. Clinical information was collected retrospectively from maternal records (maternal age, gravida, type of delivery, presence of Thick meconium stain, induced or spontaneous labour, and pregnancy complications). The KMC records provided additional information about new born infant (birth asphyxia, stages of birth asphyxia, birth weight, sex and subsequent mortality). Results: The outcome of treatment in babies with birth asphyxia showing in Recovery rate in group one (HIE I) was $18(15.79 \%$ ), in group two (HIE II) was 77(97.40) and in group three (HIE III) was 7(6.14\%) and Death ratio was in group one (HIE I) was $2(1.75 \%)$, in group two (HIE II) was $3(2.63 \%)$ and in group three (HIE III) was $7(6.14 \%)$. In the morbidity and mortality in cases of birth asphyxia the highest causes of death in stage 3(HIE III) was $5(58.33 \%)$ Preterm with Hyaline membrane disease was $3(25 \%)$ and then the higher causes of death in stage III were Neonatal sepsis 2(16.67\%). Conclusion: Birth asphyxia was one of the commonest causes of admission and mortality in SCANU and others beds in Khulna Medical College Hospital for Pediatric department. Babies with HIE Stage III had a very poor prognosis. Birth asphyxia combined with other morbidities was associated with a higher mortality. Sepsis is the commonest morbidity in cases of birth asphyxia. Maternal gravida, pregnancy complication with PROM, Thick meconium stain, APH, emergency caesarean section, pre-term and male sex were the risk factors for birth asphyxia.

Key words: Birth asphyxia, HIE, Neonatal sepsis.

Copyright $(\mathcal{2 0 2 0}$ The Author(s): This is an open-access article distributed under the terms of the Creative Commons Attribution 4.0 International License (CC BY-NC 4.0) which permits unrestricted use, distribution, and reproduction in any medium for non-commercial use provided the original author and source are credited.

\section{INTRODUCTION}

Birth asphyxia is defined by the World Health Organization "the failure to initiate and sustain breathing at birth[1]. The National Neonatology Forum of India has defined birth asphyxia as" gasping and ineffective breathing or lack of breathing at one minute after birth. The WHO has estimated that 4 million babies die during the neonatal period every year and $99 \%$ of these deaths occur in low-income and middle income countries 2 . Three major causes account for over three quarters of these deaths, serious infection (28\%) complication of preterm birth $(26 \%)$ and birth asphyxia (23\%)[2]. This estimation implies that birth asphyxia is the cause of around one million neonatal deaths each year. One of the present challenges is the lack of a gold standard for accurately defining birth asphyxia. Because of same reason the incidence of birth asphyxia is difficult to quantify. This is demonstrated by the difference in occurrence according to different studies, where the incidence ranges from 5.4/1000 live births in a Swedish study [3] to 22/100 live hospital births in an Indian study $[4,5]$. The incidence of asphyxia in full term infants varies between 2.9-9.0 cases per thousand 
in industrial countries. The incidence for birth asphyxia is much higher in developing countries [6]. Hospital based studies in Nepal [7] and South Africa8 estimated that birth asphyxia accounted for $24 \%$ and $14 \%$ of perenatal mortality respectively. However, these may substantially underestimate the burden in rural areas, where early deaths, most of which occur at home, and more likely to be under reported. Asphyxia, a lack of oxygen or an excess of carbon dioxide caused by the interruption in breathing, is the result of the failure of the gas exchange organ. There are many reasons a baby may not be able to take oxygen before, during or just after birth. A mother may have medical conditions that can lower her oxygen levels, there may be problem with the placenta that prevents enough oxygen from circulating to the fetus or the baby may be unable to breath after delivery. In mild HIE, muscle tone may be increased slightly and deep tendon reflexes may be brisk during first few days. Transient behavioral abnormalities such as poor feeding, irritability excessive crying or sleepiness may be observed. In moderately severe HIE, the infant is lethargic with significant hypotonia, and diminished deep tendon reflexes. The grasping, Moro and sucking reflexes may be sluggish or absent, seizures may occur within $24 \mathrm{hrs}$ of life. In severe HIE, stupor or coma is typical. The infant may not respond to any physical stimulus. Breathing may be irregular and the infant often requires ventilatory support. Generalized hypotonia and depressed deep tendon reflexes are common. Pupils may be diluted, fixed or poorly reactive to light, seizures occurs early and may be initially resistance to conventional treatments [9]. The aim of present study was to identify the outcome of birth asphyxia and of avoidable risk factors for neonatal encephalopathy including mortality due to birth asphyxia. Risk factors for birth asphyxia in hospital based setting in developing countries have been categorized into ante partum, intra-partum and postnatal characteristics. In this study, we identify risk factors for birth asphyxia among newborns who were admitted in the department of pediatrics at Khulna Medical College hospital, Khulna, Bangladesh from data collected retrospective with all mothers from birth asphyxia babies.

\section{OBJECTIVES}

\section{a) General objective}

- To assess the clinical outcome of birth asphyxia.

\section{b) Specific objectives}

- Identify the cause of common obstetric and neonatal risk factors

- Identify the cause of death.

\section{Methodology and Materials}

This was a retrospective study on newborns with the diagnosis of birth asphyxia which was conducted in the department of pediatrics at Khulna Medical College Hospital, Khulna, Bangladesh in the mentioned hospital were finalized as the study population. We conducted this retrospective study from Jan 2019 to December 2019. A total of 114 consecutive asphyxiated newborn who met the inclusion criteria were enrolled in the study. All newborn babies with a clinical diagnosis of birth asphyxia (newborn with history of delayed cry or APGAR score of less than 7 in 5 minutes) were included in the study. The four categorical determinants that were considered were as follows: pregnancy complications, use of induction of labour (none, oxytocin, misoprostol or both), type of delivery (normal, caesarean and vaccum) and sex of baby. In addition, five continuous determinants were measured which were as follows: age, number of antenatal (ANC) visits, gestational age, and gravida and birth weight. The outcome of birth asphyxia in respect of mortality in different stage of HIE were also determined.

\section{RESULTS}

Between Jan 2019 and Dec 2019, there were 114 live births asphyxia neonates who were clinically diagnosed previously and admitted in the department of pediatrics at Khulna Medical College hospital, Khulna, Bangladesh. In Table-1 shows there have three groups in neonates with birth asphyxia in group one (HIE I) male was $11(17.19 \%)$ and female was $14(28 \%)$ total was $25(21.93 \%$ ), in group two (HIE II) male was $44(68.75 \%)$ and female was $33(66 \%)$ total was77(67.54\%) and in group three (HIE III) male was 9(14.06) and female was 3(6\%) total was $12(10.58 \%)$. In Table 2 showing that the distribution of determinants associated factors with birth asphyxia the highest Maternal age (18-35 years) was $81(71.05 \%)$, in Gestational Age (37-42 weeks) was $85(74.56 \%)$,in Gravida (1-2) was 67(58.77\%),in Pregnancy Complications Thick meconium stain was $39(34.21 \%)$, in Induction of Labour not Done was $83(72.81 \%)$,in Mode of Delivery Spontaneous was 62(54.39\%), in Birth weight(2500-3000 kg) was $59(51.75 \%)$ and finally the highest range of participant was male $64(56.14 \%)$. The outcome of treatment in babies with birth asphyxia showing in (Table 3) Recovery rate in group one (HIE I) was $18(15.79 \%)$, in group two (HIE II) was 77(97.40) and in group three (HIE III) was $7(6.14 \%)$ and Death ratio was in group one (HIE I) was $2(1.75 \%)$, in group two (HIE II) was $3(2.63 \%)$ and in group three (HIE III) was $7(6.14 \%)$. In Table-4 the morbidity and mortality in cases of birth asphyxia the highest causes of death in stage 3(HIE III) was $5(58.33 \%)$ Preterm with Hyaline membrane disease was $3(25 \%)$ and then the higher cause of death in stage III was Neonatal sepsis $2(16.67 \%)$. 


\section{Gender Distribution}

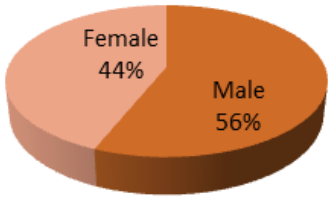

Fig-1: Gender distribution of participants $(n=114)$

Table-1: Total number of neonates with birth asphyxia $(n=114)$

\begin{tabular}{|l|c|c|c|c|c|c|}
\hline Presentation & Male & $\mathbf{\%}$ & Female & \% & Total & \% \\
\hline HIE I & 11 & 17.19 & 14 & 28 & 25 & 21.93 \\
\hline HIE II & 44 & 68.75 & 33 & 66 & 77 & 67.54 \\
\hline HIE III & 9 & 14.06 & 3 & 6 & 12 & 10.53 \\
\hline Grand Total & $\mathbf{6 4}$ & & $\mathbf{5 0}$ & & $\mathbf{1 1 4}$ & \\
\hline
\end{tabular}

Tabl-2: Distribution of determinants associated factors with birth asphyxia $(n=114)$

\begin{tabular}{|c|c|c|c|}
\hline Determinants & Category & $\begin{array}{l}\text { Number } \\
(n=114)\end{array}$ & $\begin{array}{c}\text { Percent } \\
(\%)\end{array}$ \\
\hline \multirow[t]{3}{*}{ Maternal age } & $<18$ years & 19 & 16.67 \\
\hline & 18-35 years & 81 & 71.05 \\
\hline & $>35$ years & 14 & 12.28 \\
\hline \multirow[t]{3}{*}{ Antenatal visit } & Present & 63 & 55.26 \\
\hline & Post & 30 & 26.32 \\
\hline & None & 21 & 18.42 \\
\hline \multirow[t]{3}{*}{ Gestational Age } & $<37$ weeks & 23 & 20.18 \\
\hline & 37-42 weeks & 85 & 74.56 \\
\hline & $>42$ weeks & 6 & 5.26 \\
\hline \multirow[t]{3}{*}{ Gravida } & $(1-2)$ & 67 & 58.77 \\
\hline & $(2-4)$ & 39 & 34.21 \\
\hline & $>4$ & 8 & 7.02 \\
\hline \multirow{9}{*}{$\begin{array}{c}\text { Pregnancy } \\
\text { complications }\end{array}$} & Prolapsed & 2 & 1.75 \\
\hline & Heart disease & 4 & 3.51 \\
\hline & Fetal anomaly & 3 & 2.63 \\
\hline & Thick Meconnium stain & 39 & 34.21 \\
\hline & Maternal Infection & 14 & 12.28 \\
\hline & Pre-eclampsia & 8 & 7.02 \\
\hline & APH & 16 & 14.04 \\
\hline & Placenta Previa & 7 & 6.14 \\
\hline & PROM & 21 & 18.42 \\
\hline \multirow[t]{2}{*}{ Induction of Labour } & Done & 31 & 27.19 \\
\hline & Not Done & 83 & 72.81 \\
\hline \multirow[t]{3}{*}{ Mode of Delivery } & Spontaneous & 62 & 54.39 \\
\hline & Vaccum & 10 & 8.77 \\
\hline & c-section & 42 & 36.84 \\
\hline \multirow[t]{3}{*}{ Birth weight } & $<2500 \mathrm{~kg}$ & 32 & 28.07 \\
\hline & $2500-3000 \mathrm{~kg}$ & 59 & 51.75 \\
\hline & $>3000 \mathrm{~kg}$ & 23 & 20.18 \\
\hline \multirow[t]{2}{*}{ Sex } & Male & 64 & 56.14 \\
\hline & Female & 50 & 43.86 \\
\hline
\end{tabular}

Table-3: Showing the outcome of treatment in babies with birth asphyxia ( $n=114)$

\begin{tabular}{|l|r|r|r|r|r|c|}
\hline \multirow{2}{*}{ Stages } & \multicolumn{2}{|c|}{ HIE I (20) } & \multicolumn{2}{c|}{ HIE II (80) } & \multicolumn{2}{c|}{ HIE III (14) } \\
\cline { 2 - 7 } & \multicolumn{1}{|c}{$\mathbf{N}$} & \multicolumn{1}{c|}{ \% } & \multicolumn{1}{c|}{ N } & \multicolumn{1}{c|}{$\%$} & \multicolumn{1}{c|}{ N } & \% \\
\hline Recovery & 18 & 15.79 & 77 & 67.54 & 7 & 6.14 \\
\hline Death & 2 & 1.75 & 3 & 2.63 & 7 & 6.14 \\
\hline
\end{tabular}


Table-4: Showing morbidity and mortality in cases of birth asphyxia $(n=114)$

\begin{tabular}{|c|c|c|c|}
\hline \multirow[t]{2}{*}{ HIE stages } & \multirow[t]{2}{*}{ Cases } & \multicolumn{2}{|c|}{ Mortality } \\
\hline & & $\mathrm{N}$ & $\%$ \\
\hline \multirow[t]{2}{*}{ HIE I } & Neonatal sepsis with nectrotizing enterocolitis. & 1 & 8.33 \\
\hline & Preterm with hyline membrane disease and neonatal sepsis. & 1 & 8.33 \\
\hline \multirow[t]{2}{*}{ HIE II } & Neonatal sepsis & 2 & 16.67 \\
\hline & Hydrocephalus & 1 & 8.33 \\
\hline \multirow[t]{4}{*}{ HIE III } & Neonatal Sepsis & 2 & 16.67 \\
\hline & NNS with Pneumothorax & 1 & 8.33 \\
\hline & Preterm with Hyaline membrane disease & 3 & 25 \\
\hline & Meconium aspiration syndrome & 1 & 8.33 \\
\hline
\end{tabular}

\section{DiscUSSION}

In spite of major advances in monitoring technology and knowledge of fetal and neonatal pathologies, perinatal asphyxia or more appropriately, hypoxic ischemic encephalopathy (HIE) remain a serious condition, causing significant mortality and long term morbidity. It is a tragedy for a normally developed fetus to sustain cerebral injury during the last hours of intrauterine life and to exist for many years with major handicap. It is seen that for every early neonatal death, three disabled children survive. Birth asphyxia and the hypoxic ischemic encephalopathy are one of the common neonatal problems in our country. It is the commonest cause of hospital admission of a newborn [10]. Birth asphyxia was diagnosed if there was a history of delayed crying at birth for more than 1 minute or if the 5 minute APGAR score was less than 7. The incidence of the birth asphyxia in the present study was low in compare to the study conducted by Daga[11] in Kathmandu (27\%) and Azam in Pakistan (48\%)[12]. However the rate is quite high compared with the study by Lodakhi GM in India (4.18\%)[13]. In this study the highest maternal age (18-35 years) was $81(71.05 \%)$ but this reflected the fact that this aged group represented as the most number of mothers in our obstetric service. So, this study showed that incidence of birth asphyxia was more common between 18-35 years and also shows that an increase or decrease in maternal age was not associated with any risk for birth asphyxia. This result was similar with another study done by Wael Hayel Kreisa and Zeiad Habaheh in Prince Ali Ben Al Hussein Hospital, Jordan[15] in 2005 but different results from the study done by Rachalopantana Kerno et al. at Paltani Hospital, Thailand [16] showed that birth asphyxia was significantly related to maternal age greater than 30 years. Antenatal checkups were also studied. Only 21 women (18.42\%) had no checkup during pregnancy, 63 women $(55.26 \%)$ had regular Hospital and $30(26.32 \%)$ were having Hospital visit in post. This study showed less than 70 of the women of asphyxiated babies had no checkup during pregnancy. Out of the 114 newborns, 23 babies $(20.18 \%)$ were preterm $85(74.56 \%)$ were full term and $6(5.26 \%)$ were post term. The most of the birth asphyxia cases were term babies. This study is different from the statement that post maturity is an important risk factor of birth asphyxia [12, 17]. This study is also different from the statement that term baby is a significant risk factor for birth asphyxia. When total deliveries were considered, preterm babies were quite less then term babies. So if we consider only the term babies, birth asphyxia is common among them. Out of the 114 mothers of asphyxiated babies, 67(58.77\%) were primi gravida, $39(34.21 \%)$ had less than 4 children and 8 mothers $(7.02 \%)$ were having more than 2 children. So these figures show that birth asphyxia was more common in babies delivered by primi gravida. Similar result was shown by Azam M study done in Nishtar Medical College, Multan where the primigravida was shown to be $47 \%$. But this study didn't show increase incidence of birth asphyxia with grand multipara which is different from the study done by Azam M[12] in Multan where the incidence was $34 \%$.Certain maternal risk factors were assessed by maternal self-report made during admission. Among 39(34.21\%) mothers who had complications during pregnancy more than half of them had thick meconium stain. So, thick meconium stain liquor showed increase risk factor for birth asphyxia. This result was in contrast with the study done by Anne CC Lee et al. [18] at Southern Nepal which showed meconium stained amniotic fluid had a non-significant greater risk for birth asphyxia (RR: $1.32,95 \% \mathrm{Cl}: 0.19$ to 2.16 ). This study is comparable with the study done by Lalsclottir K[19] in Iceland where $50 \%$ of the women of asphyxiated babies had meconium stain amniotic fluid. Among all the women of asphyxiated babies 21(18.42\%) had premature rupture of membrane (PROM). Among the women with complicated pregnancy, more than one third had PROM. Study done by Anne CC Lee [18] Southern Nepal and Azam M [12] at Nishtar Hospital, Multan also showed that prolonged rupture of membrane was a significant risk factor for birth asphyxia. Ante partum haemmorrhage (APH) and maternal infection was accounted to be $30(14.71 \%)$ respectively and $24(11.76 \%)$ respectively. In this study birth asphyxia was commonly seen in those mothers who had no induction of labour than in those who had induction of labour. Only 31(27.19\%) mothers of asphyxiated babies had induction of labour. The finding in this study did agree with the finding at Pattani Hospital, Thailand [16]. While most deliveries 62 (54.39\%) were normal, some $42(36.84 \%)$ had caesarean delivery and some $10(8.77 \%)$ by vacuum. Out of 114 babies, presenting with birth asphyxia 64(56.16\%) were males and50 $(43.86 \%)$ were females. This result is similar to the 
study done by Azam M in Multan [12]. The mortality rate in this study was quite high as compare to the study done in University of Calabar Teaching Hospital $(p<0.001)$.In this study mortality in HIE stage I and stage II was quite similar with the study done by M.H Haidary [14] in Rajshahi, Bangaladesh but mortality in HIE stage III was higher than other studies like M.H Haidary in Rajshahi where the mortality was only $60 \%$. The result regarding incidence of mortality in different stages of HIE was similar with one study done by Lodakhi GM in India [13]. This result was also higher than another study done by Mullign and Chawdhary where mortality due to severe birth asphyxia was $25.87 \%$. In this study Recovery rate in group one (HIE I) was $18(15.79 \%)$, in group two (HIE II) was 77(97.40) and in group three (HIE III) was 7(6.14\%).

\section{Limitations OF THE STUdy}

This was a Retrospective type of study in a single community with comparatively small number of sample size. So, the study result may not reflect the exact scenarios of the whole country.

\section{CONCLUSION AND}

\section{RECOMMENDATIONS}

Birth asphyxia is one of the commonest causes of admission and mortality in the department of pediatrics at Khulna Medical College Hospital, Khulna, Bangladesh. Among all stages of birth asphyxia, HIE stage II is the most common, then HIE stage I and finally HIE stage III. Babies with HIE Stage III had a very poor prognosis whereas HIE stage I had a very good prognosis. Sepsis is the commonest morbidity in cases of birth asphyxia. Maternal gravida, pregnancy complication with PROM, Thick meconium stain, APH, emergency caesarean section, pre-term and male sex were the risk factors for birth asphyxia. Mortality and morbidity were more common in males than in females. All around the world, birth asphyxia is one of the commonest causes of neonatal deaths and also a major cause of neonatal admissions. Without proper understanding of the various risk factors and other associated factors related to birth asphyxia, it will be difficult to develop strategies for its prevention and management. Prospective and case control studies will be necessary in future to get more scientific ideas about birth asphyxia in the context of Bangladesh.

\section{REFERENCES}

1. World Health organization. Basic Newborn Resuscitation; a Practical Guide. World Health Organization: Geneva. 1997 [Accessed February 27, $2007 . \quad$ Avilable http:www.who.int/reproductivehealth/publication/MSM 98 /introduction en.html.

2. Lawn JE, Cousens S, Zupan J.4 million neonatal deaths: when ? where? why? Lancet. 2005;
365:891- 900.

3. Thornberg E, Thiringer K, Odeback A, Milson I. Birth Asphyxia; incidence, clinical course and outcome in a Swedish population. Acta Paediatr. 1995;84:927-32.

4. Futrakul S, Praisawanna P, Thaitumyanon P. Risk factor for Hyposic- ischemic encephalopathy in asphysiated newborn infant. J Med Assoc Thai. 2006;89:322-8.

5. Chandre S, Ramji S, Thirupurum S, Perinatal asphyxia; multivariate analysis of risk factors in haopital birth. Indian Pediatr. 1997;34:206-12.

6. Nelson KB, Ellenberg J. Apgar scores as precidtors of chronic neurological disability. Pediatrics. 1981;68:36-44.

7. Ellis M, Manandhar DS, Manandhar N, Wyatt J, Balam AJ, Costello AM stillbirths and neonatal encephalopathy in kathmandu, Nepal: An estimate of the contribution of birth asphyxia to perinatal mortality in low income urban population. Paediatr Perinat Epidermiol. 2000;14:39-52.

8. Buchmann EJ, Pallinson RC, Myathikazi N.Intrapartum - related birth asphyxia in South Africa lessons from the first national perinatal care survey. S Af Med J. 2002; 92:897-901.

9. Richard E. Behrman, Robert M. Kliegman, Editors. Hypoxia-Ischemia, Nelson text book of pediatric 17th ed. United states of America. Hal B Jenson; 2004: 566-568.

10. Memon IA. Neonatal resuscitation. J Coll Physiol Surg Pak. 1995;5(4):163-164.

11. Daga As, Daga Sr, Patole SK. Risk assessment in birth asphyxia. Trop Pediatr. 1990;36:34-39.

12. Azam M, Malik F, Khan P. Birth asphyxia risk factors. The professional. 2004;11(4):416-423.

13. Ladakhi GM, Mubank M, Nabi B, Hassan M, Sethi AS. Neonatal risk factors and outcome of birth asphyxia. JK Practioner. 2000;7(4):267-70.

14. Haidary MH, Hussian A, Ahmed S, Kasem A. Clinical profile of Birth asphyxia in Rajshahi medical collage hospital. J Teachers Assoc. 2005; 18: 106- 108.

15. Weal Hayel Khreisa, Zeiad Habahbeh, Risk factors of birth asphyxia: A study at Prince Ali Ben AlHussein Hospital Jod. Pak J Med Sci. 2005;21(1):30- 4.

16. Rachatapantanakorn $\mathrm{O}$, Tongkumchum $\mathrm{P}$, Chaisukant Y, Factor associated with birth asphyxia in Pattani Hospital Thailand. Songkla Med J. 2005;23(1):17-27.

17. Gomella TL, Cunning MD, Perinatal asphyxia. The Professional. 1999;480-89.

18. Anne CC-Lee. Risk Factors for Neonatal Mortality due to Birth Ashyxia in Southern Nepal. Pediatrics. 2008;121(5):1381-90.

19. Lalsclottir K, Dagbjartsson A, Thorkellsson T, Hardottric H; Birth asphyxia and hypoxic ischemic encephalopathy, incidence and obstetric risk factors. Laeknabladid. 2007;93(9):595-60. 